\title{
Multicultural Placement Programme of Student-Teachers During Pre-Internship: A Case Study
}

\author{
Sudarshan Mishra, Ph.D. \\ Head, Department of Education, Ravenshaw University, Cuttack, Odisha \\ Sasmita Paramanik \\ Ph.D. Scholar, Department of Education, Ravenshaw University, Cuttack, Odisha
}

\begin{abstract}
The uniqueness of two-Year B.Ed. programme of Regional Institute of Education, Bhubaneswar, Odisha (RIE) which is a constituent body of NCERT, New Delhi is that, it gives importance to field experience and practical exposures for trainees in the form of multicultural placement, internship in teaching and field work with community. During pre-internship phase, the student teachers are given the exposure to various schools through Multicultural Placement Programme (MCPP). The MCPP has three aspects: Pre-conference for 2 days in the institute; Multi-cultural placement for 15 days in three types of schools (Urban, Rural and Tribal) and a half-day day post-conference in the institute. The present study is an attempt to understand about the processes of organizing various activities and the problems associated in organising MCPP in RIE. The present study adopted ethnographic case study design. Out of three groups, one group of 24 student-teachers were the sample of the present study. The sites for the present study were RIE and three Government schools of Balasore district from three locations i.e., tribal, urban and rural areas. The data collection instruments were observation schedules, Interview schedules and focus group discussions with student-teachers. During observation, it is found that some student-teachers are not taking much interest in different activities. There is hardly any critical observation by student teachers. This may be because of lack of proper guidance and continuous monitoring by cooperating teachers and supervisors. Except the coordinator of the programme, nobody is serious about MCPP. The studentteachers could not realise the cultural diversity inside and outside the classroom. Emphasis was given on pedagogy and not culture-specific pedagogy. Non-Odia background student teachers faced serious problem when they are placed in Odia medium schools. At last, the investigators put their suggestions to improve the process of conducting MCPP.
\end{abstract}

Keywords: multicultural placement programme (MCPP); student teachers; pre-internship phase; cooperating schools.

DOI: $10.7176 /$ RHSS/9-9-02

Publication date:May $31^{\text {st }} 2019$

\section{Introduction}

The quality of a nation depends upon the quality of its citizens. The quality of citizens depends upon the quality of their education. The quality of education rests upon the quality of teachers and the quality of teachers depends upon the quality of teacher education among many other factors. The learning society offers many and varied opportunities for learning at school and in economic, social and cultural life. The teachers are now required to update their knowledge every day. The Education Commission (1964-66, p.67) observed; "A sound programme of professional Education of teachers is essential for the qualitative improvement of education". Investment in teacher Education can yield very rich dividends because the financial resources required are small when measured against the resulting improvement in the education of millions.

Teacher education programmes operate at two levels: Pre-service and In-service. Pre-service teacher education programme is of different types on the basis of level of school education like, elementary teacher education and secondary teacher education programmes. In India, Secondary teacher education programmes are designed to prepare pupil teachers for secondary and higher secondary schools. Programmes are two year Bachelor of Education (B.Ed.), 3-year Integrated B.Ed. M.Ed. and 4-year Integrated B.A.B.Ed./B.Sc.B.Ed. degree.

Internship is an integral part of any pre-service teacher education programme for professional preparation of pupil teachers in a school environment, planned and co-ordinated by the teacher education institution in cooperation with one or more school systems. Intern is a prospective teacher under the guidance of a teacher educator involved in all the activities of the school simultaneously with his/her teaching duties. According to NCTE (2014, p.116), school internship would be a part of the broad curricular area of engagement with the field and shall be designed to lead to development of a broad repertoire of perspective, professional capacities, teacher sensibilities and skills. The curriculum of B.Ed. shall provide for sustained engagement with learners and the school (including engaging in continuous and comprehensive assessment for learning), thereby creating a synergy with schools in neighbourhood throughout the year. Student-teachers shall be equipped to cater to 
diverse needs of learners in schools. These activities shall be organised for 4 weeks in the first year of the course. Students are to be actively engaged in teaching for 16 weeks in the final year of the course. They shall be engaged at two levels, namely, upper primary (class VI-VIII) and secondary (class XI-X), or senior secondary with at least 16 weeks in secondary/ senior secondary classes. They should be provided opportunities to teach in schools with systematic supervisory support and feedback from faculty. Internship in schools will be for a minimum duration of 20 weeks for two year programme (4 weeks in the first year and 16 weeks in the second year). This should also include, besides practice teaching, an initial phase of one week for observing a regular classroom with a regular teacher and would also include peer observations, teacher observations and faculty observations of practice lessons.

NCERT is an apex resource organization to bring qualitative improvement in school education. It undertakes various activities like conducting research, developing curriculum, preparing textbooks and other teaching materials, providing training to the teachers and teacher educators. NCERT through its five Regional Institutes of Education, provides pre-service teacher education programme. Development of innovative programme of pre-service teacher education is one of the major concerns of the Regional Institutes of Education. The Regional Institute of Education, Bhubaneswar (RIE) is a constituent body of NCERT. Its 2 Year B.Ed. Programme is a model pre-service teacher education programme throughout the eastern region. The uniqueness of this programme is that, it gives importance to field experience and practical exposures for trainees in the form of multicultural placement, internship in teaching and field work with community. The internship in teaching is the core of the 2 year B.Ed. programme. Its internship programme is very systematic and rigorous. Internship consists of 3 phases such as pre-internship, during and post-internship phase.

At the beginning of pre-internship phase, activities for developing of core teaching skills are carried out. After learning about different skills of teaching and practicing these in simulating conditions in the first semester, the student teachers are given the exposure to various schools through MCPP (Regional Institute of Education, 2015, p.65). The MCPP has three aspects:

1. Pre-conference for 2 days in the institute

2. Multi-cultural placement for 15 days in three types of schools (Urban Rural and Tribal) and

3. One day post-conference in the institute.

During the pre-conference, besides the student teachers, the practicing teachers from co-operating schools and faculty members of the RIE discuss about the strategies to be adopted in the schools to accomplish the activities during the multi-cultural placement. During their placement in different schools, student teachers are required to conduct certain activities/assignments. These activities are (i) Learning of teaching-learning process through observation of lessons taught by regular teachers in the school (ii) observation and collection of data about schools processes i.e. day-to-day activities taken place in the school, for example, working of the library, process of organizing co-scholastic activities, sports, social and cultural activities functioning of laboratory, organization of school assembly and above all the school management, (iii) taking substitute (arrangement) classes, (iv) preparation and use of teaching learning materials/teaching aids for classroom teaching, (v) development of sample lesson plans and delivery of it and (vi) conducting case studies in the school. During post-conference in the RIE, student-teachers give their feedback which is supposed to be placed in the Report so as to reflect the students' perception of the programme. This is helpful in the modification of the next programme.

MCPP enables student-teachers to apply and verify for themselves the practicability of the theoretical knowledge of foundation courses, content of various academic subjects, methods and techniques of curriculum transaction and evaluation, class and school management in actual school situations. In order to provide school exposure in various cultural backgrounds of the society to the student-teachers, they are placed in urban schools, rural schools and tribal schools for 15 days on rotation. The investigators are interested to study about the processes of organizing various activities and the problems associated in organising MCPP in RIE. The major objectives of the study are:

1. To study the activities organised during Multicultural Placement Programme (MCPP) for pupil-teachers of RIE, Bhubaneswar, India.

2. To study the problems associated in organising Multicultural Placement Programme (MCPP).

\section{Methodology}

The present study adopted ethnographic case study design. The case for the present study is Regional Institute of Education, Bhubaneswar, India which is a constituent body of NCERT, New Delhi,. Only Two-year B.Ed. programme is selected for the present study. Purposive sampling method has been adopted in selecting the sample. Multi-Cultural placement programme was divided into three phases like, Pre-conference, during and post-conference. Two clusters were selected by RIE for MCPP: one from Balasore district of Odisha state and the other from Gaya district of Bihar state. A total of 126 student-teachers participated in MCPP, out of which 54 were placed in Gaya and 72 were placed in Balasore. Further, 72 students were divided into three groups-A, B 
and $\mathrm{C}$ consisting of 24 students each. Only Group-C of 24 student-teachers was the sample of the present study. Three Government schools of Balasore district were selected by RIE from three areas: tribal, urban and rural for MCPP. Each group went through three different schools on rotation. All these twenty four student teachers were selected for interview. Four focus group discussions (FGDs) consisting of 4 to 6 student-teachers were conducted in each school. Twelve co-operating teachers (four from each school) were selected purposively for interview. All the four teacher-educators including programme co-ordinator were selected for interview.

The investigator developed and used three tools for collection of data. They are (1) Observation schedules (2) Interview schedules and (3) focus group discussion with student-Teachers. Four Observation Schedules were prepared as follows: 1 . Observation schedule for Pre-Conference, 2. Observation schedule during MCPP and 3. Observation schedule for post-conference. Observation schedule for pre-conference was used for observing the process of pre- conference, which was conducted for 2 days after completion of simulated teaching in RIE. It included the components like, discussion about activities to be performed by the student-teachers, discussion session between student-teachers and the teacher-educators, criticism lesson delivery by the student-teachers, etc. Observation schedule during MCPP consisted of: Activities conducted by student teacher; Observation of school processes; substitute class by student teachers; Preparation and use of TLMs; Process of development of lesson plan; Conducting case study; Evaluation work by student teachers; and teaching by regular teachers. Observation schedule during post-conference includes the components like, feedback from student-teachers; observation of teaching aids exhibitions; evaluation and scheme of assessment; suggestions from various stake holders; etc. Three interview schedules were prepared: 1. interview schedule for Teacher-Educators, 2 . interview schedule for co-operating school teachers and 3. interview schedule for student-teachers. Interview schedule for teachereducators consisted of seven different aspects: plan, involvement, guidance, feedback, benefits, satisfaction and problems. Interview schedule for cooperating school-teachers consisted of: involvement of co-operating school teachers, benefit, difficulty, feedback, evaluation process, facilities provided by the school, performance of the student-teacher and experience gained by cooperating school teachers. Interview schedule for student-teachers during MCPP consisted of dimensions like, pre-internship conference, involvement, experience, suggestion, activity, cultural diversity, satisfaction, need of skill class, need of document activities and prepared nine questions. Focus group discussion with student-teacher during MCPP covers areas like, teaching skill, peerevaluation and observation, preparation, foundation for internship programme, role of supervisor, feedback, experiences of student-teacher, benefits from cooperating teachers, suitability for curriculum, importance of case study and cultivation of culture.

The field study was carried over during the month of February, 2014 for a period of 15 days and 5 days for each school. All the activities done by the student-teachers in different schools related to their study were observed. The collected data were analysed by using content analysis techniques. Triangulation was used for cross checking and validation of data collected through various sources.

\section{Result}

Pre-conference during MCPP

Before going to the multicultural placement programme, a two-day conference was organized in RIE, Bhubaneswar. There were five sessions. Co-operating school teachers along with headmasters from different schools, all the student-teachers of 2-year B.Ed. programme, Supervisors, Resource persons, and Programme coordinator were participated in this conference. The student teachers were apprised of the following points during the conference.

- $\quad$ Purpose of MCPP

- Rules and regulations of the schools

- Records to be maintained for evaluation

- Process of observation of lessons taught by regular teachers in the school

- Observation and collection of data about school processes

- Taking substitute (arrangement) classes

- Preparation and use of teaching learning materials

- Development of sample lesson plans in different subject areas

- Conducting case studies

- Role of cooperating teachers and headmasters

Interaction session was arranged with the cooperating teachers and student-teachers. Cooperating teachers shared their previous year's experiences with MCPP and student-teachers.

Teacher educators discussed about multicultural placement programme and its objectives; activities to be organized in different schools; types of facilities for student-teachers in school; role of school teachers, headmasters; preparation of comprehensive report on school processes; development of teaching learning materials; etc. Resource persons discussed about different aspects related to school internship such as, school 
environment, development and delivery of lesson plans, developing concept mapping, activities related to the multicultural placement programme, school culture, substitution teaching, qualitative feedback from supervisors, cooperative learning, school processes, development of teaching learning materials, case study, etc.

A criticism lesson was organised in which student-teachers delivered lessons in their respective subjects. In the criticism class, student-teachers were very attentive and wrote important points and sub-points of the topic taught in the class. While interviewing with student-teachers after criticism, it was found that they became more confident. They are now more conscious about upgrading content knowledge; improved skill of asking relevant questions to the students, managed time appropriately, found out weaknesses, can deal heterogeneous classes more effectively and can use varieties of teaching strategies.

The Coordinator of the programme introduced the Cooperating teachers coming from different schools. Cooperating teachers discussed with student-teachers about how to develop Lesson plan. Student-teachers were actively participating in the conference. Some questions raised by the student-teachers were clarified by the resource persons with appropriate examples. However, it was found that teacher-educators discussed with the students-teachers about lesson plan formats which were different from each other. So, student teachers were confused. There should be uniform lesson plan format for skill classes and for pre-conference. It was also revealed that student-teachers were confused in developing concept maps and other activities. They were going with this confusion to schools during MCPP and facing problems in the school. Pre-conference should be organized in a systematic way, so that student-teachers can understand everything clearly. Teacher-educators should deliver the demonstration lessons and discuss with the students-teachers so that they can follow them. They should also be oriented to make TLMs easily by using materials collected from surroundings. Teacher educators should monitor continuously about the process of developing lesson plans. Before going to deliver the criticism lesson, teacher-educators should verify their lesson plan. Since, criticism lessons are delivered in school, school teachers also gave their feedback for improvement.

\section{Observation of teaching of regular teachers during $M C P P$}

While observing teaching of regular teachers by student-teachers during MCPP, it was found that studentteachers were writing their observation in the format given by RIE. Student teachers were very attentive in the class. From their observation notes, it was found that most of them were writing about teachers and their method of teaching: how did the teachers introduce the lesson, how did they ask questions, how did they cite examples related to student's real life experiences, how did they use Blackboard, voice modulation of teachers, audibility, student participation, use of TLMs, home assignments and suggestions for improvement. Student-teachers discussed among themselves about content knowledge of teachers, blackboard work, audibility of teachers' voice, type of examples cited, student involvement, type of reinforcement, questioning skills, stimulus-variation, assessment of students' homework copies, methods of teaching, clarification of students' doubts, time management, evaluation process, etc.

\section{Observation of substitution class by student-teachers}

Student-teachers were also observing the substitution class delivered by their peer student-teachers. Observation was focussed on introduction to lesson, relating with previous knowledge, audibility, blackboard work, citing examples, student participation, etc. At the end, headmaster gave constructive feedback to students.

It was found that student teachers were using TLMs during presentation of lesson. But letter size in TLMs was very small and not visible to all. They could not cite suitable examples to explain the concepts. Mostly, they were following lecture-cum-discussion method. Blackboard work was good. However, it was not visible to back-benchers. Student teachers (observers) were discussing among themselves which distract the student teachers who involved in substitute teaching. Students were not actively participating in teaching learning process. Student teachers were hardly giving any examples and reinforcement and there was no stimulusvariation in the class. There was no continuity in presenting lesson. Time management was very poor. Most often, they could not get time for summarization and evaluation part was missing.

After completion of teaching, students-teachers gave constructive feedback to their friends for improvement related to introduction of the lesson, use of TLMs, quality of home assignments, quality of content related examples, questioning skills, use of black board, use of positive reinforcement, participation of students, audibility and clarity of voice, etc.

Apart from observing teaching of peer teachers and regular teachers, student-teachers were collecting data from school teachers and staff members about organisation of school assembly, functioning of library and laboratory, organization of various curricular and co-curricular activities like, sports, social and cultural activities, celebration of important days and festivals, etc. Student-teachers arranged a drama in the school for all the students and staff. The drama was dedicated to slow learners. Student-teachers were observing and writing all the activities very systematically.

Supervisors were not regular and they observed the classes for a few minutes. However, they discussed 
about critical points in a separate room. There was hardly any feedback from the supervisor or student-teachers. Non-Odia student teachers were facing language related problem since, schools were Odia medium. Supervisors should solve this problem.

Nevertheless, in few instances, it was found that student teachers were using activity method and students were participating actively. Student-teachers used learner-centred methods. TLMs were used appropriately. Appropriate examples were given to clarity the concepts. Use of Blackboard was good and visible to all. Reinforcement was appropriate. During recapitulation, evaluation was made appropriately. Relevant questions were asked.

\section{Post-conference during MCPP}

After completion of multicultural placement programme (MCPP) in various schools, a half-day post-conference session was organized in RIE. Student-teachers, supervisors, Principal, Dean of instruction and other faculty members were present in the conference. All the group leaders read their report and share their experiences and gave certain feedbacks for further improvement of the programme. The Principal, Dean of instructions and other faculty members also shared their experience and gave suggestions to improve the quality of the programme in future. The written comments and suggestions given by various Cooperating schools were also discussed in the conference. The coordinator discussed about strengths and weaknesses of the programme and suggested what can be done in the next MCPP.

Group leaders were asked to submit all records/ assignments/ evaluation sheets, etc. to the Coordinator for final evaluation. Follow-up, remedial and strengthening activities were given by the institute according to the feedback received from various corners. Group leaders shared their experiences about the behaviour of the headmasters in the schools, cooperating teachers and students, journey, accommodation, facilities, observation of morning assembly, drill class and other activities in the school. According to group leaders, due to more number of student teachers, there was problem of allotment of classes to student teachers. Again, as the syllabus was already completed, students were not interested to listen to student teachers.

Student teachers felt that they gained experiences in: how to manage classroom, how to teach through Odia medium, how to develop and use low cost and no cost TLMs, conducting case study, etc. Since, all the Cooperating teachers did not participate in the pre-conference, they were not aware of the rules, duties and responsibilities for which student teachers had to face problems.

According to headmasters of various schools, had MCPP organized at the beginning of the session, students would have been benefited more.

It is felt that co-operating teachers should participate and share their experience in the post-conference. It should be one whole day programme. Student-teachers other than the group leaders should also get an opportunity to share their experiences.

\section{Perception of Teacher Educators}

According to teacher educators, MCPP is the preparatory stage of internship programme. Every year, proforma of the programme are revised on the basis of feedback from the previous year student teachers and faculty members. Generally, student-teachers are deputed to remote areas in order to make them acquaint with the local culture. They were provided with actual classroom situation in different cultural context. They evaluate studentteachers' performance continuously. During MCPP, continuous and comprehensive evaluation system is practiced where both supervisors and cooperating teachers evaluate the student teachers. Supervisors are expected to maintain dairies and these diaries are helpful for evaluation. This programme is very helpful to student teachers in developing a positive attitude towards their work and they develop the competency to adjust in diverse situations.

Criticism lesson and demonstration lesson are quite helpful for student-teachers. In criticism lessons, student teachers were given feedback about their strengths and limitations for improvement.

However, cooperating teachers instead of guiding student teachers during the entire multicultural placement programme, they are only taking benefit of student-teachers in terms of assigning number of substitute classes. Therefore, the intention of multicultural placement programme is not realized.

\section{Perception of cooperating school teachers}

According to cooperating school teachers, due to MCPP, school students are getting new exposure. They might have been bored with old faces. Now, they see new and young faces who are creating a friendly atmosphere in the classroom and facilitate students for knowledge construction. Student teachers teach with love and affection. They help in improving students' content knowledge and creativity. Students actively participate in the classroom. School teachers do not use TLMs in the classroom. But student teachers use TLMs. This makes student learning effective. Students freely interact with student teachers and get additional information. Subject teachers give feedback about teaching, lesson plan, TLMs and case study which help student teachers to improve. 
Teachers also try to sort out any problem faced by student teachers. Teachers also evaluate student-teachers by observing their methods of teaching, interaction with students, classroom management and lesson plan. They also regularly give feedback to the supervisor about student teachers.

MCPP develops value of cultural integrity, as the student-teachers are interacting with different types of students and also involving in life of the school. Since, student-teachers are having multi-cultural background with different languages, culture, etc., students are exposed to teaching in different languages like, Odia, Hindi and English. This has created a friendly atmosphere in the classroom with students and creates interest in students. Students are impressed by these pupil teachers. As the student teachers are involved in all the activities including classroom teaching, it helps in developing skills like, cooperation, involvement, interaction, participation, etc.

However, According to cooperating school teachers, the duration of multicultural programme should be longer so that trainees will be involved in school activities in a better way and they can complete all the assignments in a better way. They can also be involved in different programmes of the schools such as RMSA, mid-day meal scheme, SSA Scheme, etc. Cultural integrity requires time to spend with students and school. Five-day duration in one school in multicultural setting is not sufficient. It should be at least of 10 days duration.

Few cooperating school teachers are not satisfied with MCPP. According to them, school is facing a lot of difficulties. Student teachers are taking classes according to the normal routine. As a result, they are not able to complete the syllabus in time. Student teachers are not taking revision classes, do not provide any additional information and not involving students in co-curricular activities. Student-teachers do not give attention to back benchers and weaker students. They do not clarify the doubts of students.

\section{Perception of student teachers}

According to student teachers, pre-conference is quite beneficial as they get an idea what to do during MCPP. By delivering criticism lessons, they are more confident. By participating in interaction session, they could clarify their doubts. During MCPP, they face real classroom situation which help them in developing teaching skills, practicing different methods, and assessing student performance.

MCPP gives an exposure to understand the school practises in three different schools culture. It also develops certain skills and values like, school management, discipline, punctuality, adjustment, cooperation, sharing of experiences, how to deal with diverse learners, how to prepare a lesson plan, arrangement of substitution class, involvement with students, etc. They also got exposure to organizing remedial classes, morning assembly, drill class, functions, debates, competitions, and other cocurricular activities.

Peer group played a major role in developing performance of student teachers. They point out strengths and weaknesses, rectify mistakes, weaknesses and share their content knowledge related to the topic.

However, supervisors should come to school regularly. He/she should stay with them so that students can interact with him/her as and when required and get suggestions consistently. Student teachers can share their experiences also. Supervisor should be an expert both in content and pedagogy. Principal should depute such supervisors only. In the post-conference, not only group leaders but also other student teachers should get an opportunity to share their experience of MCPP.

Skill classes should be continued after the MCPP. During MCPP, student teachers gain varieties of experiences which will be useful in the skill classes. This will also help them for internship program.

\section{Discussion}

During observation, it is found that some student-teachers are not taking much interest in different activities. They are taking MCPP casually just to complete as part of the curriculum. They are not seriously involved in the activities for which multicultural placement programme became a ritual. There is hardly any critical observation by student teachers. Some of them feel it as a kind of picnic where they are going, staying, merry making and coming back. This may be because of lack of proper guidance and continuous monitoring by cooperating teachers and supervisors. Except the coordinator of the programme, nobody is serious about multicultural placement programme. The coordinators with lot of financial crunch, has to identify schools in different locations who will cooperate and maintain a balance among cooperating schools, teachers, RIE and pupil teachers. Arranging safe and hygienic accommodation with arrangement of foods and other amenities is a challenge for coordinator. It should be team work. This is also observed while interacting with teacher educators.

The culture part in MCPP is missing. The student-teacher could not realise the cultural diversity inside and outside the classroom. Emphasis was given on pedagogy and not culture-specific pedagogy. This was very much realised during post-conference. Student teachers could not distinctively mention about the differential exposure they got from three types of schools.

Pre-conference should be organised in workshop mode where student teachers will learn by doing some activities under the supervision of faculty members and cooperating teachers.

Sizeable student teachers were from non-Odia background. However, all the multicultural schools under 
observations were from Odia medium. Student-teachers followed CBSE text-books, developed lesson plans in English in their criticism lesson. But they have to face serious problem when they are placed in Odia medium schools.

Though the RIE arranges three different schools to get exposure from three different culture i.e. urban, rural, tribal etc. so that student teachers will get an exposure to rural, urban and culture, but none of the schools are located in tribal areas. So student teachers do not get opportunity to experience the tribal culture and environment.

15 days duration of MCPP is not sufficient to realize it objectives. It should be enhanced to at least 30 days with 10 days in each school. There should be an interaction session between the student teachers and teacher educators during middle of MCPP programme. During MCPP, student teachers always seek for feedback from teacher educators but teacher educators remain absent most of the time. Hence, teacher educators should stay with the student teachers during MCPP.

The cooperating school teachers should also be invited for the post conference programme of MCPP to share their experience.

(The design for the present study is influenced by Thapan (2006) and Sibia (2006). Hence, the authors are highly thankful to Thapan (2006) and Sibia (2006) whose ethnographic studies on schools inspired a lot towards the present study.)

\section{References}

Ministry of Education, Govt. of India (1966). Report of the Education Commission 1964-66 Education and National Development. New Delhi: Author.

NCTE (2014). Norms and standards for Bachelor of Education programme leading to the Bachelor of Education (B.Ed.) Degree. Retrieved from: http://www.ncte-india.org/ncte_new/regulation2014/english/appendix4.pdf Regional Institute of Education (NCERT) (2015). Two year Bachelor of Education (B.Ed.) Programme with CBCS (Regulations and Courses of Study). Bhubaneswar, India: Author. Retrieved from: http://riebbs.ac.in/images/documents/B-Ed-2year-cbcs.pdf

Sibia, A. (2006). Life at Mirambika A free progress school. New Delhi: NCERT.

Thapan, M. (2006). Life at School: An Ethnographic Study. New Delhi: Oxford University Press.

\section{About the Authors}

Dr. Sudarshan Mishra is presently Head, Department of Education, Ravenshaw University, Cuttack, Odisha, India. He has been teaching subjects like, Sociology of Education, Trends and Issues in Education and Research Methodology in Education for last fifteen years to undergraduate, postgraduate and Doctoral students. His major area of research interest is Elementary Education.

Ms. Sasmita Paramanik is a Ph.D. Scholar in Department of Education, Ravenshaw University, Cuttack, Odisha, India. She is doing her research work in preservice teacher education. 